\title{
Metaimagens na televisão e vanguardas: as vinhetas da Rede Globo e MTV ${ }^{1}$
}

Felipe Muanis ${ }^{2}$

\begin{abstract}
Resumo: A partir das discussões sobre paleo e neo-televisão, apontadas por Umberto Eco, Francesco Casetti e Roger Odin, pretende-se levantar indagações sobre a validade de interrupção das metaimagens televisivas, tomando como exemplo as vinhetas institucionais da Rede Globo de Televisão e da MTV. A associação das poéticas das vinhetas com alguns recursos estéticos utilizados por artistas vanguardistas do início do século $X X$, bem como suas possibilidades narrativas e não narrativas, fundamentam a discussão. Umberto Eco, John Caldwell, Anika Schoemann e Flávio Cauduro serão autores analisados.
\end{abstract}

Palavras-chave: paleo-televisão, neo-televisão, ritmo, poder de interrupção, modos de atenção.

Abstract: From discussions about paleo and neo-television pointed by Umberto Eco, Francesco Casetti and Roger Odin, we intend to inquire about the interruption ability of television metaimages, analyzing Rede Globo's and MTV's art-breaks. The association of artbreaks poetics with some aesthetical recourses used by avantgarde artists from the beginning of XX century, as their narrative and non-narrative possibilities, base the argument. Umberto Eco, John Caldwell, Anika Schoemann and Flávio Cauduro will be the authors analyzed.

Keywords: paleo-television, neo-television, rhythm, interruption power, attention ways. 
O trabalho que ora se desenvolve busca examinar a metaimagem televisiva, com particular atenção para as vinhetas institucionais da Rede Globo de Televisão e MTV Brasil. Para tanto, faz-se necessário, como primeiro passo, definir metaimagens enquanto imagens autorreferentes que não necessitam de um texto, que se sustentam apenas por sua própria imagem, que são ambíguas, imprecisas e resgatam uma certa "selvageria". A televisão, de acordo com Arlindo Machado e Marta Lucía Vélez (2007), fica muitas vezes restrita às análises conteudísticas ou, ainda, às particularidades da transmissão em direto. Sem retirar a importância das análises tradicionalmente feitas, os autores apontam para a importância da busca de outros caminhos exploratórios, que possam dizer mais sobre as características da imagem televisiva do o que normalmente se discute.

Junto a essas considerações, e adicionando as leituras de John Thornton Caldwell (1995), é possível observar uma série de mudanças na imagem da televisão ao longo do tempo. Essas transformações coincidem com o que outros teóricos, tais como Umberto Eco, Francesco Cassetti e Roger Odin, apontam como a passagem da paleo para a neo-televisão. É nessa mudança que se amplifica o uso de metaimagens, especialmente vinhetas e comerciais localizados nos intervalos dos programas.

Apesar das metaimagens poderem ser vistas como as emissões características da transmissão em fluxo e de sua visualização no espaço dos intervalos justificar, do ponto de vista comercial, a realização de programas atrativos para o espectador, vinhetas e comerciais são vistos normalmente como produtos periféricos, que têm como função principal separar blocos de programas televisivos. Dessa forma, tais veiculações oferecem visibilidade aos seus patrocinadores, gerando o lucro da emissora com a venda de espaço publicitário que, por sua vez, viabilizaria o programa. Mas sua importância maior residiria no fato de separarem a programação, permeando uma narrativa com outros textos, permitindo um distanciamento maior do espectador em relação à representação que está sendo vista. Nessa 
linha, discute-se também se as metaimagens separam ou conectam o fluxo televisivo, ou seja, os programas e seus blocos.

Mary Ann Doane afirma, no entanto, que as metaimagens na televisão não têm mais o poder de interrupção que tinham no passado. A autora argumenta que as breaking news e a "catástrofe" desempenham tal função de interrupção do fluxo. Contudo, observando outras variáveis - por exemplo, o modo como o espectador se relaciona com a televisão - podemos dizer que mesmo hoje, com seu poder de interrupção mais limitado, as metaimagens, em alguns momentos, cumprem o papel de quebra da narrativa e ainda mantêm tal função original.

Nesse sentido, as metaimagens tenderiam mais à separação quando interrompem emissões de narrativas fechadas que normalmente não foram feitas especificamente para a televisão, como no caso das exibições de filmes originários do cinema. Ou seja, esses filmes foram feitos para serem exibidos de uma única vez, sem qualquer intervalo que crie uma interrupção abrupta em sua forma e narrativa. Em produtos feitos para a televisão, o seu próprio formato favorece certa naturalidade da interrupção. Assim, o uso das metaimagens também pode desempenhar uma função mais conectiva ao unir os blocos abertos de uma emissão televisiva - soapoperas ou novelas - que foi planejada para receber o intervalo, preparando o espectador e o mantendo em suspenso para o próximo bloco. Uma prova são as marcas claras de intervalos que podem ser percebidas durante um seriado de televisão visto em dvd, no qual não se exibem os comerciais. Nesses casos, portanto, as metaimagens nos intervalos exerceriam uma função prioritária de conectivos entre as emissões e seus blocos.

Assim, mesmo que erroneamente, se considerarmos que assistir televisão é apenas colocar-se diante do fluxo concordaremos com a ideia de que as metaimagens não teriam mais o valor de interrupção. Mas partindo do pressuposto de que o modo de atenção diante da televisão contemporânea não é sempre transversal e em fluxo, somos levados a concluir que as metaimagens, 
dependendo da postura que o espectador tenha diante da televisão, seja paleo ou neo-televisiva, continuam mantendo o seu valor de interrupção. Ainda que não deixemos de levar em conta os conceitos de paleo e neo-televisão, que se referem a alterações ocorridas na televisão ao longo do tempo, procuramos transferir a análise de tais mudanças para o campo da recepção, conferindo assim uma ênfase maior aos modos de atenção do telespectador.

Caldwell também distingue dois momentos da televisão, que podem ser associados respectivamente aos conceitos de paleo e neo-televisão, propostos primeiramente por Umberto Eco. Caldwell associa uma imagem de intensidade zero a uma imagem sem muita profundidade ou acabamento, correspondente ao período da televisão clássica. Por outro lado, a televisão-estilo, ou televisãoexcesso, seria, para o autor, o momento seguinte em que a imagem é mais trabalhada. É onde a imagem televisiva adquire mais profundidade e se aproxima da imagem cinemática, ganhando os recursos de computação gráfica e da imagem digital. Essa transformação, de acordo com os autores analisados, acontece com mais intensidade em meados da década de 1980, e pode ser vista com maior clareza nas vinhetas institucionais dos canais de televisão.

\section{Vanguarda e ritmo}

Partindo de Umberto Eco e seu conceito de "obra aberta", assim como de John Fiske, que diferencia as intertextualidades da televisão, podemos pensar que apesar da televisão trabalhar com um grande número de narrativas abertas, seus intervalos agregam desde narrativas mais fechadas (comerciais), como narrativas mais abertas ou não narrativas (vinhetas). As vinhetas podem ser uma narrativa fechada, como algumas da MTV, por exemplo, ou até uma não narrativa, como é o caso das vinhetas da Rede Globo e da maior parte das grandes redes de televisão. Tais vinhetas carregam em sua imagem marcas da passagem da paleo para a neo-televisão. Pelo fato de frequentemente se utilizar da imagem sintética, a vinheta caminhou rapidamente para a televisão- 
estilo através de uma imagem do excesso, o que altera a perspectiva de sua concepção. Segundo Caldwell, a computação gráfica também seria uma marca da transição entre paleo e neo-televisão.

Ao tomarmos como objeto de análise as vinhetas da Rede Globo de Televisão e da MTV, percebemos que a principal distinção entre elas se dá pela estética modernista da primeira e pós-modernista da segunda. O fato de as vinhetas da Rede Globo serem tributárias do modernismo bauhausiano e do design gráfico suíço conduz à não narratividade, ao plano sequência, às formas geométricas feitas em computação gráfica. É criado, assim, um diálogo com uma poética que se tornou frequente nas vinhetas das grandes emissoras, especialmente na transição entre paleo e neo-televisão. Algumas de suas estratégias de movimento e ritmo são tributárias propriamente de características presentes na obra de alguns cineastas experimentais das vanguardas de 1920 , nas quais não eram utilizadas formas figurativas nem seus referenciais precisos de tamanho, posicionamento e movimento para o espectador. As vinhetas da Rede Globo mostram abertura e não narratividade à semelhança de inúmeros filmes vanguardistas: ambos privilegiam cor, movimento e ritmo, ao invés de estabelecer referenciais para o espectador.

O texto não narrativo abre mão, justamente, das relações de causa e efeito proporcionadas por um texto oral (falas de personagens e locuções texto de prosa) ou por um texto visual (regras e linguagem de câmera) sobre uma linha de tempo. Assim, o som possível no audiovisual não narrativo é formado pelo uso de palavras aparentemente desconexas, ruídos, música, ou ainda, o efeito de silêncio ${ }^{3}$. Todas essas possibilidades sonoras também estão presentes no audiovisual narrativo, mas estão sempre atreladas a um texto referencial predominante, que gera a relação de causa e efeito, e é a espinha dorsal da narrativa audiovisual. Alguns exemplos da proximidade entre o som - ou a intencional ausência dele - e o audiovisual não narrativo parecem claros no cinema ou na televisão. Walther Ruttmann, Hans Richter, Oskar Fischinger, Fernand Léger, Marcel Duchamp (inclusive em parceria com John Cage), Viking 
Eggeling, e posteriormente Harry Smith, fizeram diversas experiências com a relação entre som e imagem, como se vê em seus filmes. Ainda que com propostas e poéticas diferentes, como afirma Adams Sitney, os trabalhos desses autores são centrais para se pensar o cinema gráfico (2002, p. 232). De fato, para Françoise Parfait, o cinema clássico é o responsável principal por contar histórias, ficando a cargo da videoarte e do cinema experimental questionar e romper com essa função que "remete à questão do regime de credibilidade da narração"4 (2001, p. 84). Assim, a música, os ruídos e as dissonâncias, por também se afastarem do uso da palavra nos trabalhos de videoarte, cumprem um papel determinante para romper as amarras entre imagem e narrativa. Com isso, a associação entre imagens e sons ganha maior liberdade de combinações.

Os cineastas vanguardistas da década de 1920 muitas vezes eram oriundos das artes plásticas e descobriram no cinema a possibilidade de imprimir movimento às formas. Para reforçar essa ideia nas imagens, apesar de distintas propostas, todos conceitualizavam as possibilidades sonoras inclusive o silêncio - associando-as às imagens, como etapa importante da criação cinematográfica. Também músico ${ }^{5}$, Walther Ruttmann entendia que a sua cinematografia se baseava em um parentesco entre a pintura e a dança, em que formas, superfície, claridade e escuridão levavam ao movimento através do ritmo. O movimento das figuras de Ruttmann, para Brigitte Hein e Wulf Herzogenrath, exibe-se

(...) deslizando, pulsando, pingando, crescendo, tremulando etc. Aparece em sequências e ritmos que com complexidades orgânicas e disciplina textual, são comparáveis com a multiplicidade da música de orquestra sinfônica, já que repetem seus temas e "melodias" e variam sua velocidade, densidade e harmonia (e no original possivelmente também as cores) ${ }^{6}$ (apud SCHOEMANN, 2003, p. 118).

Do mesmo modo, Viking Eggeling explorava o movimento, o ritmo e o tempo em sua pintura, com influência do movimento Dadaísta, o que também foi experimentado em seu único filme, Diagonal Symphonie, de 1925. Eggeling, no entanto, prescindiu do acompanhamento musical por acreditar que a música 
poderia distrair a apreensão de linhas e formas. Ainda assim, o raciocínio para o seu trabalho guardaria semelhanças com o movimento musical. De acordo com Anika Schoemann, "Eggeling entendia seu trabalho como uma espécie de 'música visual'7 (2003, p. 121) em que o movimento acontecia como uma 'música silenciosa'"' (2003, p. 122). Junto com Eggeling, Hans Richter também buscava novos caminhos para a arte através de filmes abstratos. No primeiro, conceitualmente silencioso, explorava o movimento a partir da variação de tamanho das formas geométricas, oferecendo ao espectador uma sensação de profundidade. Já no segundo, Rhytmus 23 (1923-1924), de acordo com Schoemann, "a música conferia a ele vivacidade e assegurava ritmo, com diferentes formas ainda que não estivessem em sincronia com a música"8 (2003, p. 126). Em seguida, realizou filmes em que misturava animação e material filmado, já fazendo uso de música, como no filme Inflation (1928), aproximando-se do caminho estético utilizado por Fernand Léger em Le Ballett Mécanique (1924) e René Clair em Entr'Acte (1924).

Foi após maravilhar-se com a primeira exibição de Lichtspiel Opus $I$, de Walther Ruttmann, que Oskar Fischinger, estudante de música, arquitetura, design e engenharia, passou a fazer cinema. De acordo com o Center for Visual Music $^{9}$, os comerciais em animação, realizados por Fischinger, são considerados por muitos como os precursores do videoclipe:

(...) Fischinger usou uma técnica de camadas de celulóide para animar formas visuais equivalentes aos conceitos musicais de ritmo, harmonia e contraponto. Colocou em uso uma técnica "divisionista" de mudança de cores quadro a quadro para obter uma luminosidade particular e matizes cromáticas que não podiam ser produzidas pelos métodos normais de animação fotográfica. (...) Por fim, Allegreto foi reconhecida como uma das peças mais completas na história da música visual ${ }^{10}$.

Annika Schoemann (2003) lembra ainda que, por esse motivo, erroneamente qualificavam o seu trabalho apenas como ilustrações para as músicas. Seu objetivo seria justamente o oposto, centrado no desejo de despertar novas impressões no espectador através de um maior número de possibilidades 
visuais. Para tanto se basearia em linhas que realmente dançavam ao sabor da música, impregnadas de ritmo e sincronicidade.

Pode-se notar que os vanguardistas do cinema dos anos 1920, pensavam imagem e meio, com uma curiosidade técnica e com um raciocínio muitas vezes sonoro e/ou musical. Talvez não seja um deslocamento inapropriado, comparar, guardadas as devidas proporções, a prosa e a poesia com o audiovisual narrativo e não narrativo, respectivamente. Nesse sentido, Roland Barthes traz uma contribuição oportuna para a discussão que se apresenta:

Com efeito, a poesia moderna, já que devemos opô-la à poesia clássica e a qualquer prosa, destrói a natureza espontaneamente funcional da linguagem para deixar subsistir-lhe apenas os alicerces lexicais. Das relações, ela só conserva o movimento, a música, não a verdade (BARTHES, 1974, p. 143).

Barthes trata das relações de linguagem verbal que seriam, em sua acepção, o sustentáculo do texto clássico. É claro que produtos audiovisuais que não privilegiem as relações de linguagem verbal, como alguns filmes das vanguardas da década de 1920 ou o trabalho dos videoartistas dos anos 1960, obedecem a outros referenciais. Nesse caso, é possível perceber o movimento, a música e a sua junção no ritmo, como um referencial. Nenhum desses artistas pensava as possibilidades criativas da imagem dissociadas do som e do que ele poderia contribuir com o desenvolvimento de novas poéticas. Assim, é possível constatar a importância que o som tem não apenas para a imagem da televisão, mas também como ponto importante das investigações videográficas que Ihe sucederam, sugerindo, inclusive, o caminho do audiovisual abstrato. Esse caminho acabou sendo absorvido e reciclado, posteriormente, em outros segmentos, comerciais ou não, seja no videoclipe ou nas instalações de videoarte.

\section{As vinhetas institucionais da Rede Globo e MTV}

Esses espaços de construção em que os sons favorecem a não narrativa são evidentes no cinema experimental, na videoarte e no universo dos vjs, 
seja através de sons ou ruídos. Caberia então perguntar: a televisão, com suas inseparáveis características comerciais, poderia abrigar este tipo de imagem audiovisual? É possível ver em algumas vinhetas institucionais da Rede Globo e da MTV, a presença dessas estruturas não narrativas em que as imagens se constroem e se desdobram prioritariamente junto ao tempo da música?

O produto audiovisual em que essa construção se torna mais evidente é o videoclipe - que, não coincidentemente, é o ponto de partida da MTV. Foi com o sucesso do canal como o seu meio preferencial de exibição, que se profissionalizou o videoclipe - que não deixa de ser um produto comercial. Nos anos 2000, os videoclipes têm imagens elaboradas, uma linguagem própria e que, cada vez menos, obedece a um roteiro determinado, sem necessariamente estar calcado na exibição dos músicos ou componentes da banda. Contudo é no espaço das vinhetas, veiculadas nesta emissora, que é possível ver uma maior variedade de poéticas no intervalo televisivo. São as vinhetas que mais diretamente dialogam com estratégias não narrativas experimentadas nas vanguardas dos anos 1920. É possível dizer que parecem repetir, em seus diversos momentos, viabilizados pela técnica e pela própria transformação do meio televisivo e de sua imagem, o movimento do olhar do pintor no percurso da arte. Se a vinheta nasce bidimensional e plana através da captação de simples cartelas desenhadas com no máximo um movimento lateral da imagem, em um segundo momento ela ganha profundidade e perspectiva direcionando o espectador para o fundo da imagem, para onde voam um ou mais elementos. Por fim, em um terceiro momento, assim como as assemblages da pop-art, as vinhetas apresentam novos elementos, possibilitando a percepção de que as mesmas aparentam saltar da tela e ganham relevo. Este processo também elimina a distância entre obra e espectador, fazendo com que este tenha a sensação de que adentra a imagem e não apenas de que a aprecia de um só ângulo à distância. Poderia se pensar, desse modo, que apesar das técnicas e dos meios diferenciados, o caminho das transformações na imagem da televisão foi muito similar ao da mudança dos pontos de vista na própria história da arte. 
A Rede Globo, por exemplo, tem vinhetas normalmente abertas, que contrastam com o fechamento da maioria dos comerciais e com as diversas emissões. Por ter uma variedade maior de programas e por exibir muitos filmes feitos para o cinema, as metaimagens de seus intervalos têm maior poder de interrupção do que de conexão, resgatando o seu poder de paleo-televisão. O fato das vinhetas da Globo manterem a estética do plano-sequência, desprezando qualquer necessidade de referencialidade espaço-temporal, sem se prender às convenções clássicas de eixo de câmera para orientar o espectador, fazem dela um produto com uma poética totalmente diferente tanto das narrativas fechadas presentes na TV (filmes) como das narrativas abertas (seriados e telenovelas), que seguem os sistemas tradicionais de decupagem clássica e referencialização do espectador. Assim se evidencia o contraste entre suas vinhetas, as emissões e mesmo as metaimagens mais fechadas (os comerciais), caracterizando um poder de interrupção maior do que na MTV.

É possível observar nas vinhetas da Rede Globo de Televisão o uso de cores e esferas em movimento em um fundo infinito, priorizando o ritmo e a ligação sincrônica, além da ausência de estabelecimento de referenciais de espaços, movimento e tempo. Tais características remetem para a obra do cineasta alemão Oskar Fischinger. O primeiro trabalho em que Fischinger constrói essa relação é Study n.7 (1930-1931), no qual formas abstratas, ao ritmo da música, movimentam-se na perspectiva de um espaço infinito profundo. Nesse filme, Fischinger radicaliza alguns experimentos realizados anteriormente por diversos cineastas, como por exemplo Hans Richter e Fernand Léger, que criavam movimento através da mudança de tamanhos e formas em um espaço infinito, sugerindo profundidade. Um de seus filmes é especialmente interessante por abrigar as diversas possibilidades de movimento da imagem, presentes posteriormente nas vinhetas da Globo: em Kreise (1933), publicidade abstrata e um dos primeiros filmes coloridos feitos na Europa, Fischinger criou o movimento de esferas a partir de uma bola que se desloca pelo eixo $z$ da imagem, com um fundo infinito, e depois para fora da tela, extrapolando para o visível. Fischinger ainda utilizou cores e círculos coloridos em movimento, 
utilizando um sistema de separação de três cores chamado Gaspar Color, que ele mesmo ajudou a elaborar.
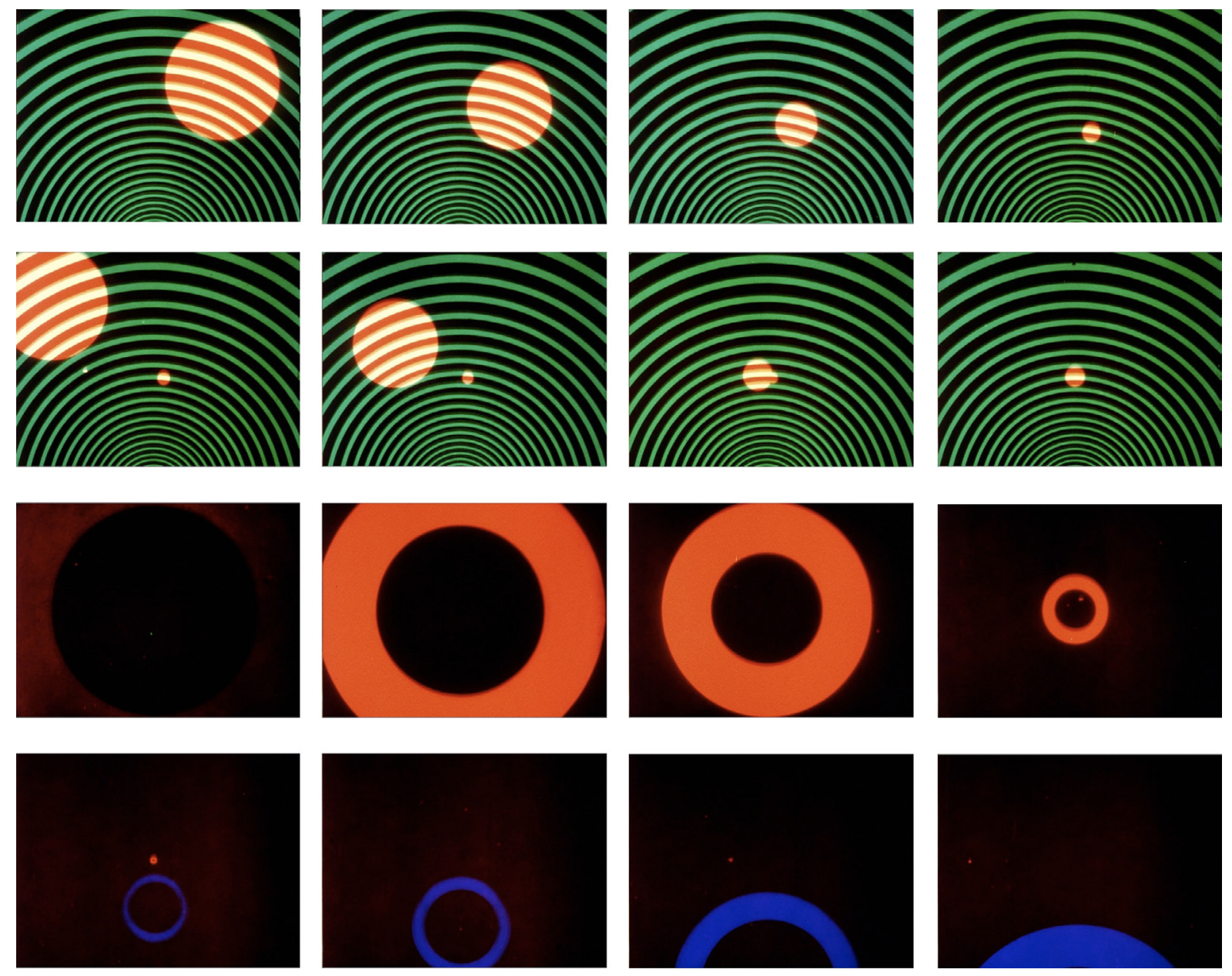

Oskar Fischinger: Kreise (1933)

No entanto, mesmo que exista o predomínio de características comuns às vinhetas da Globo, é igualmente possível observar uma distinção nestes mesmos produtos, apontando para a constituição de três fases específicas. Nos primeiros dez anos, além de ser um logotipo diferente, a imagem se movimentava pelas laterais fazendo uso de apenas um plano de profundidade. Não há nenhuma sugestão de relevo no logotipo ou de movimento para o fundo do quadro. As imagens das vinhetas da Rede Globo apontam para uma relação mais estreita com a imagem moderna. Essa relação pode ser observada, sobretudo, no 
período definido como a segunda fase das vinhetas da emissora, compreendidas entre 1976 e 1990, no qual a imagem passa a ser simulada por computadores e explora, cada vez mais os seus recursos, ampliando as possibilidades de televisualidade e os campos de leitura do espectador.

O design moderno ficou marcado pela relação entre formas simples e objetos geométricos, em oposição a um design muitas vezes ascético que se opunha ao barroco ou ao ornamento. O bem-vindo uso da tecnologia possibilitava chegar a um funcionalismo através do design. Superfície metálica ou transparente, simulava relevo e movimento em direção ao fundo do quadro, reforçando a ilusão de profundidade ${ }^{11}$. Sua imagem, portanto, sofre influência dessas características e faculta o aumento do referencial visual, desestabilizando o espectador. Tais características aparecem claramente nas metaimagens e especialmente nas vinhetas da Rede Globo.
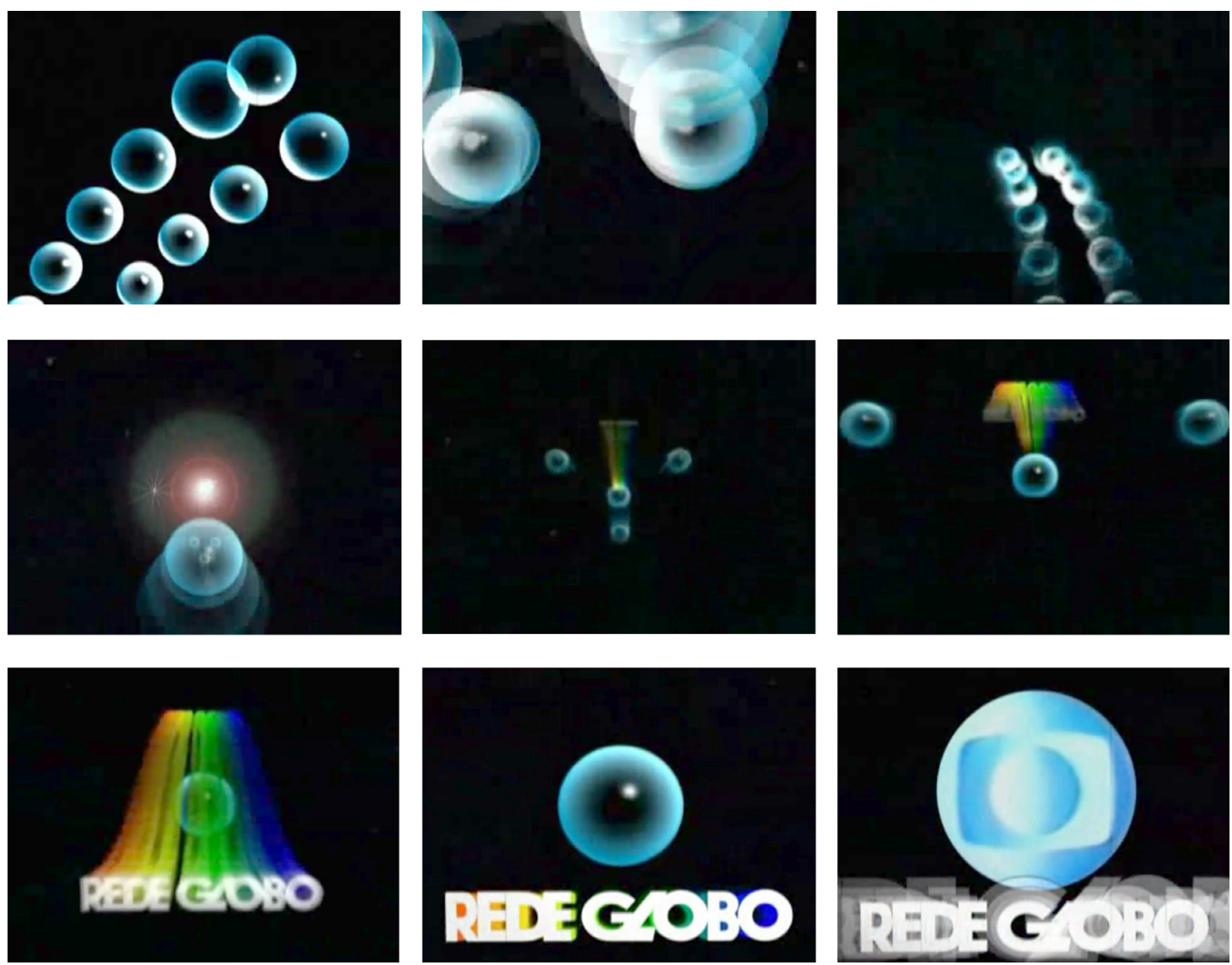

Vinheta da Rede Globo, segunda fase (1977) 
A terceira fase das vinhetas da Rede Globo é uma combinação de tudo que já foi utilizado e experimentado no decorrer do seu temp

o: imagem captada e imagem sintética, superfícies transparentes e reflexivas, movimentos que se deslocam entre o ponto final da assinatura e o fundo, bem como para as extremidades do quadro, passando pelo espectador, conectando a imagem ao visível. É a partir da virada do milênio que as vinhetas da Rede Globo assumem sua pós-modernidade possível, ainda que atrelada a sua poética tradicional, misturando na mesma vinheta diversos elementos que antes eram vistos, normalmente, em separado.

Por manter uma poética moderna, não narrativa, em que formas e cores se combinam por meio do ritmo e do movimento, pode-se dizer que as vinhetas da Globo, apesar de seguirem praticamente a mesma poética com algumas variações, desde 1975 até os dias de hoje, têm mais poder de interrupção. Essas formas geométricas e autorreferentes interrompem as construções narrativas clássicas e conteudísticas que compreendem a grande maioria dos programas televisivos.

As vinhetas da MTV apresentam uma estética distinta, absorvendo grande variedade de tendências, dentre elas a própria estética modernista. Algumas vinhetas podem mostrar abertura e outras fechamento, narratividade e não narratividade. A técnica da MTV é não se fixar em nenhuma estética. Mais do que isso, as vinhetas deste canal mostram valor e função cambiante com relação às outras metaimagens do intervalo e às emissões - em suma, ao fluxo. Isso acontece com as vinhetas que se assemelham e se confundem com programas, como Monkey Brain, de Amir Admoni; com um comercial, como Patê de fígado de ganso; ou ainda com uma soap opera, que é o caso da série de vinhetas Náufrago.

Pode-se dizer que as vinhetas da MTV, mais do que a sua programação, absorveram características pós-modernas e se constituem como descendentes 
do vídeo experimental. Se as vinhetas, tradicionalmente, podem funcionar como separadores e conectivos, nas vinhetas da MTV elas realizam uma função até mesmo oposta, posto que prendem a atenção do telespectador pela variedade de formatos, pelo ineditismo e até mesmo por serem surpreendentemente narrativas. Todas essas possibilidades reforçam uma identidade de metaimagem própria da vinheta da MTV que, de certa forma, corrompe a poética habitual das vinhetas, ao agregar em si diferentes formatos, textos e técnicas distintas.

Ainda que muitas apresentem pequenas estruturas narrativas, existem também muitas vinhetas não narrativas na MTV. Estas, contudo, em nada se assemelham às vinhetas de emissoras tradicionais. Pelo contrário, são mais próximas de algumas construções da videoarte, em que se exploram o ritmo e o movimento. Ao contrário da Rede Globo, que utiliza formas geométricas e cores em movimento, muitas das vinhetas não narrativas envolvem objetos em que é possível identificar uma representação. 

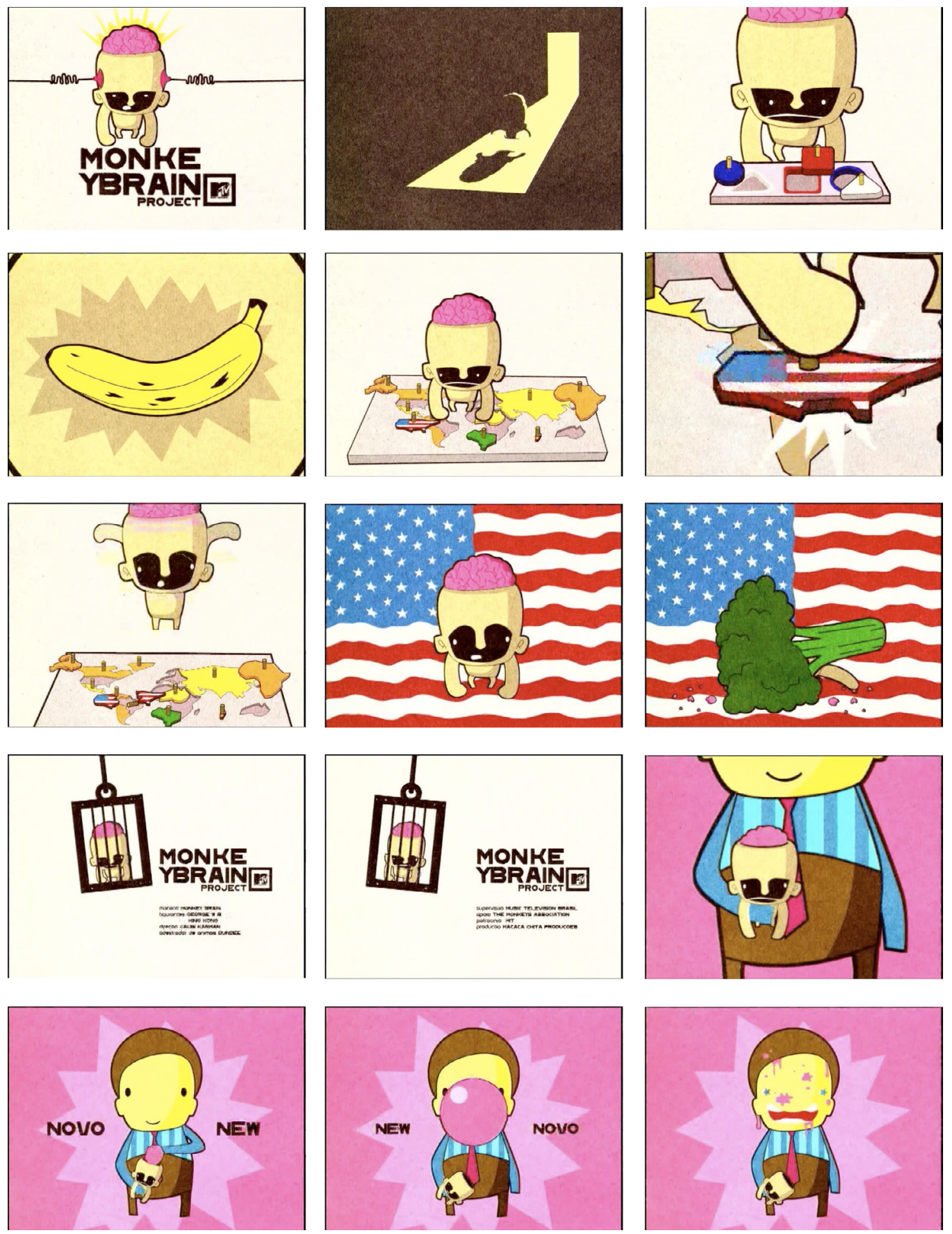

Amir Admoni: Monkey Brain 

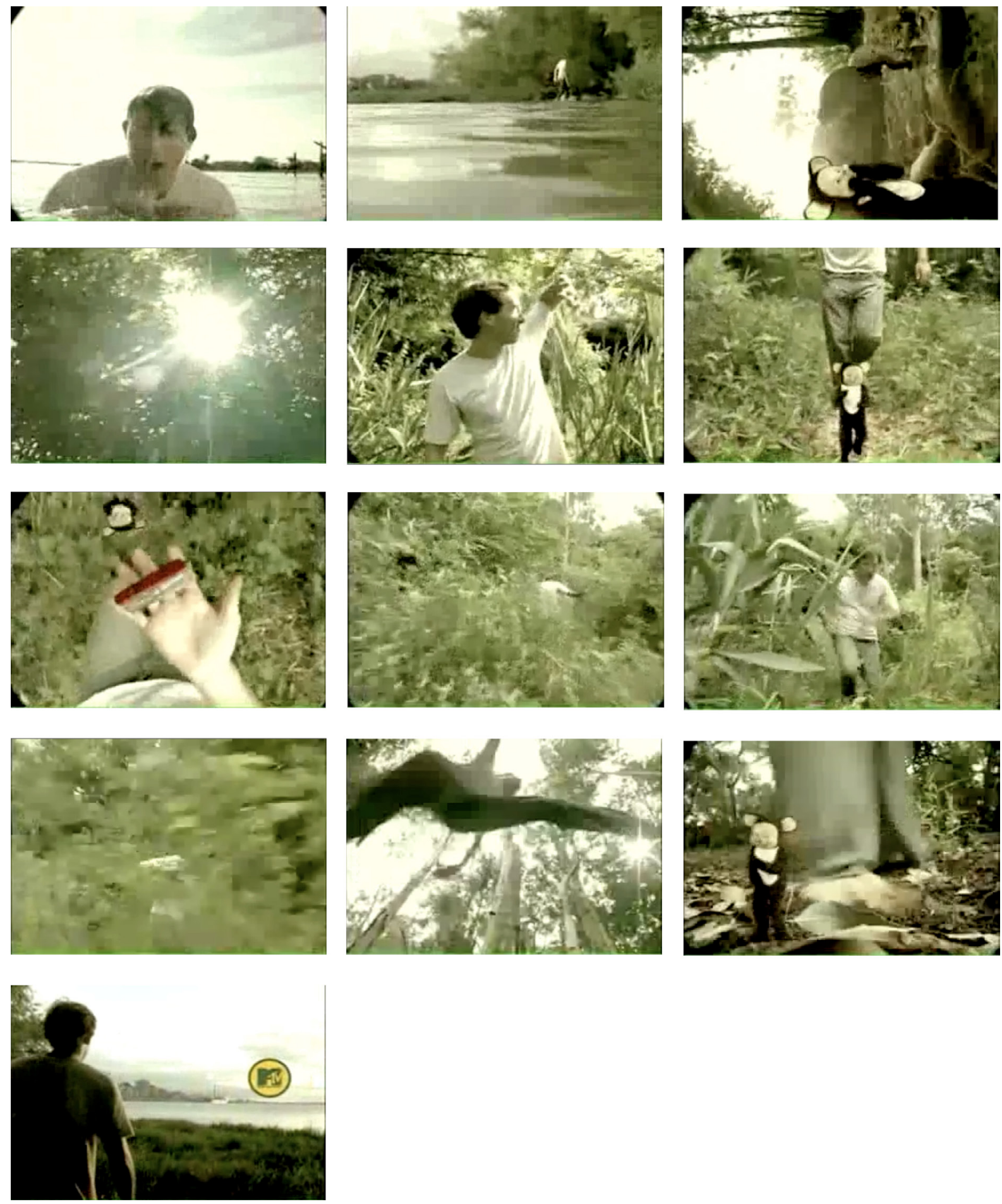

Náufrago

Também é possível, em muitos desses casos, identificar características referenciais para o espectador, como enquadramento, eixo, velocidade e 
movimentação de câmera. Mesmo assim, não há uma relação de causa e consequência entre as imagens, que muitas vezes se sucedem apenas pelo seu potencial iconológico: sua cor, forma, movimento e ritmo aliado à música.

A MTV, entretanto, mudou com o tempo. Ela era uma emissora que se assumia fluxo, ou seja, tinha primordialmente programas pouco estruturados que eram coletâneas de videoclipes. Seus intervalos apresentavam vinhetas que, esteticamente, não tinham grandes distinções com o que acabou de ser visto no bloco anterior da emissão transmitida. O valor de interrupção dessas vinhetas era mínimo, pois sua grade já era fragmentada. No Brasil, a MTV, inicialmente, pouco apresentava comerciais. No entanto, ainda que em passos comedidos o canal seguiu as televisões do resto do mundo, fazendo programas, muitos deles no formato de programas de auditório destinados ao público jovem. Nesse caso, os intervalos funcionam como conectivos, na medida em que foram programas feitos para a televisão, pensando na estrutura de intervalos. É importante lembrar que a MTV não exibe filmes, mas programas de auditório. É na interrupção de produtos que não foram feitos especificamente para a televisão, como os filmes, que as metaimagens e vinhetas de televisão mais se aproximariam de separadores. Sendo assim, pela semelhança de sua estética e pelo diálogo formal com as emissões, as vinhetas da MTV, apesar de extremamente variadas, não teriam um grande valor de interrupção, por se assemelhar e até mesmo se confundir com a sua própria programação.

\section{Considerações finais}

A transformação da imagem na televisão segue caminhos similares e ao mesmo tempo complementares aos da pintura, o que demonstra a necessidade de não apenas estudá-la como um campo de imagens variadas, mas também de pensar as metaimagens na sua relação com as transformações da imagem em um sentido amplo. Nela é possível encontrar imagens representativas ou não representativas, tanto narrativas fechadas como narrativas abertas e não 
narrativas. A televisão, conforme sugere Aznar, ao mostrar vinhetas em um vasto número de cidades do interior do Brasil, leva imagens autorreferentes que são fruto de uma longa reflexão e história no campo da arte, até comunidades distantes: imagens-ritmo, textos abertos, mas ainda assim populares. Guardadas as suas devidas proporções, a televisão pode, de diferentes maneiras, em função de seu dispositivo e dos seus mecanismos diferenciados de comunicação, levar novas formas de audiovisual a lugares remotos em que a videoarte dificilmente chega. Assim como as aberturas de programas feitas por Carybé e Rui de Oliveira ${ }^{12}$, inúmeras experimentações da videoarte absorvidas pela televisão chegam a mais pessoas em um contexto de maior comunicação. Mais do que isso, a televisão, e aqui priorizando as vinhetas com as suas diversas possibilidades estéticas, leva não apenas produtos audiovisuais para os recônditos do país, mas também possibilita distintos modos de ver e se relacionar com uma imagem a partir de uma tela.

Autorreferentes e sem depender necessariamente de textos, as metaimagens têm sua força justamente por sua ambiguidade e por sua grande capacidade de agregar diferentes poéticas que induzem o espectador à dúvida, abrindo ainda mais os textos televisivos. Este caráter dúbio ocorre, por exemplo, nas vinhetas da Rede Globo quando estas agregam a imagem de um programa para só depois se revelarem como uma vinheta. Também é possível identificar tal característica quando esta é genericamente auto referenciada e absorve imagens de outras mídias para se construir, caracterizando sua imprecisão e ambiguidade. Por fim, quando a sua reflexividade depende da natureza da representação visual, ou seja, quando a metaimagem, por agregar formatos da própria televisão, confunde-se com um programa, como é o caso de algumas vinhetas da MTV. A metaimagem, nesse caso, não é nem emissão nem vinheta, mas é um híbrido dos dois. Como, afinal, afirmar se este produto é central ou periférico na televisão, se não podemos defini-lo e nem estabelecer uma dialética entre ele, as emissões e os produtos dos intervalos? 
Lembrando Heráclito e Aristóteles, Lyotard afirma que "uma polissemia resulta da ausência de indicações sobre as pausas" ${ }^{13}$ (2002, p. 215) e lembra que Mallarmé deixou de usar pontuação em seus poemas, pois a própria rítmica já seria suficiente. Pontuação remetia à prosa e estava atrelada à significação do texto, enquanto o poeta queria que se chegasse ao "desenho de uma figura" (2002, p. 215). As metaimagens nos intervalos televisivos funcionam como um híbrido, como algo que ocupa um espaço próprio cuja riqueza está justamente em sua polissemia e em misturar legibilidade e forma, resultando em um produto com limites confusos. Exemplo disto são as vinhetas Monkey Brain e a série Náufrago, da MTV. Qual o limite possível para classificar tais produções como vinhetas e não programas, uma vez que em Monkey Brain são apresentados os créditos iniciais e finais? Para exemplificar esse espaço diferenciado que agrega discurso e figura, Lyotard lembra o pintor Paul Klee:

Klee fornece ao objeto e ao traço, todo um outro terreno de comunicação, não é nem o texto reconhecível de aparência visível, nem a escritura geométrica da tela plástica, mas um lugar (ou um não lugar) obtido graças aos procedimentos como a revogação sistemática às regras da percepção e da concepção, o deslocamento de objetos fora de seu espaço de origem, a simultaneidade do sucessivo, a co-afirmação do contrário, a condensação de constituintes distintos, a colocação em correspondência do que passa por desconhecido ${ }^{14}$ (LYOTARD, 2002, p. 231).

Ao relacionar essa proposição às metaimagens, é preciso levar em conta que tudo vai depender não apenas de sua forma e poética, mas da maneira como o espectador estiver experienciando a televisão. 


\section{Referências}

BARTHES, R. O grau zero da escritura. São Paulo: Cultrix, 1974.

CALDWELL, J. T. Televisuality: style, crisis, and authority in American Television. New Jersey, Rutgers, 1995.

CAUDURO, F. V. "Design gráfico \& pós-modernidade". In: MARTINS, F. M.; MACHADO, J. (orgs.). A genealogia do virtual: comunicação, cultura e tecnologias do imaginário. Porto Alegre: Sulina, 2004, pp. 43-60.

CASETTI, F. \& ODIN, R. "De la paléo- à la néo-télèvision". In: Communications: Télévision mutations. no 51, 1990, pp. 9-26.

DOANE, M. A. "Information, Krise, Katastrophe". In: MELLENCAMP, P. (ed.). Logics of television: essays in cultural criticism. Bloomington: Indiana University Press, 1990.

ECO, U. A obra aberta. São Paulo: Perspectiva, 2005.

Viagem na irrealidade cotidiana. Rio de Janeiro: Nova Fronteira. 1984.

FISKE, J. Television culture. New York: Routledge, 2006.

LYOTARD, J.-F. Discours, figure. Langres: Klincksieck, 2002.

MACHADO, A.; VÉLEZ, M. L. "Questões metodológicas relacionadas com a televisão". E-Compós. Revista da Associação Nacional dos Programas de Pós-Graduação em Comunicação. no 8, abril de 2007.

SCHOEMANN, A. Der Deutsche Animationsfilm: Von den Anfängen bis zum Gegenwart 1909-2001. Sankt Augustin: Gardez!, 2003. 
1 Trabalho apresentado ao Grupo de Trabalho Cultura das Mídias do XX Encontro da Associação Nacional de Programas de Pós-Graduação em Comunicação (Compós), na Universidade Federal do Rio Grande do Sul (Porto Alegre-RS, junho de 2011).

2 Professor de televisão e mídias digitais do Departamento de Cinema e Vídeo da Universidade Federal Fluminense (UFF). Doutor em Comunicação Social pela Universidade Federal de Minas Gerais (UFMG). Email: muanis@mac.com.

3 Trabalha-se com as definições de Angél Rodríguez, especialmente para ruído e silêncio, que têm conceitos fugidios. Para o primeiro, o autor se baseia no conceito de Zwicker e Feldtkeller, que definem o ruído "como um som sem altura tonal nem diferenciação temporal definidas" (2006, p. 178). Com relação ao silêncio, o autor ressalta que seria impossível um silêncio absoluto, que em qualquer situação existiria o som, ainda que de baixas frequências e que não possa ser ouvido. Rodríguez prefere trabalhar com o conceito de efeito de silêncio, no qual o espectador do audiovisual interpretaria que existe um silêncio, comparado a outros sons e entenderia que uma intensidade de som de menos de $30 \mathrm{~dB}$, por uma duração não menor do que 3 segundos constituiria não uma pausa e sim um efeito de silêncio, seja ele com uso sintático, naturalista ou dramático (2006, p. 187).

Tradução livre.

5 Apesar de ter estudado arquitetura e trabalhar em diversas áreas do cinema, Ruttman demonstrava grande interesse por música, desde a juventude, quando aprendeu a tocar violoncelo.

6 Tradução livre.

7 Idem.

8 Ibidem.

9 Dvd "Oskar Fischinger: ten films", produzido pelo Center for Visual Music, 2006.

10 Tradução livre. http://www.centerforvisualmusic.org/Fischinger/OFBio.htm Acessado em: 20/06/2009.

11 A imagem das vinhetas da Rede Globo em que uma esfera desliza sobre um fundo negro encontra paralelos formais com construções imagéticas de filmes de ficção-científica, como 2001, uma odisseia no espaço; e as séries de filmes Guerra nas estrelas e Jornada nas estrelas.

12 O artista plástico Carybé realizou vinhetas de televisão para a TVE Bahia em 1996 e Ruy de Oliveira fez as vinhetas de abertura para a TVE entre 1978 e 1983, e as vinhetas de abertura e encerramento da série infantil Sítio do Pica-pau Amarelo, na Rede Globo de Televisão, exibida entre 1976 e 1980.

13 Tradução livre.

14 Idem. 